\title{
Recovery of the rabbit's conditioned nictitating membrane response without direct reinforcement after extinction
}

\author{
GABRIELLE WEIDEMANN and E. JAMES KEHOE \\ University of New South Wales, Sydney, Australia
}

\begin{abstract}
Three experiments demonstrated that, following the extinction of an established conditioned stimulus (CSA - e.g., tone), the pairing of a novel, cross-modal stimulus (CSB-e.g., light) with the unconditioned stimulus (US) results in strong recovery of responding to the extinguished CSA. Experiment 1 demonstrated that the recovery of responding to CSA is not the result of US reinstatement but is attributable to pairings of CSB with the US. Experiment 2 demonstrated that the recovery of responding is specific to CSA and is not the result of cross-modal generalization. Experiment 3 revealed that a large number of CSB-US pairings in Stage 1 significantly reduced the amount of recovery to CSA during subsequent CSB-US trials. Experiment 3 also provided unexpected evidence of cross-modal secondary extinction. The extinction and subsequent recovery of responding seen in the present experiments is discussed with respect to possible contributions from contextual associations, CS processing, US processing, conditioned response expression, and layered excitatory associations.
\end{abstract}

The conditioned response (CR) that results from pairing a conditioned stimulus (CS) with an unconditioned stimulus (US) is reduced if the CS is repeatedly presented in the absence of the US. Intuitively, this loss of performance to an extinguished CS seems to result from the loss of the original excitatory association. However, even after complete elimination of the $\mathrm{CR}$, various techniques have revealed that extinction does not completely erase the underlying excitatory association. For example, performance to an extinguished CS can reappear when the CS is presented after a period of rest (spontaneous recovery; Pavlov, 1927 , p. 58) or when it is presented outside the context in which extinction occurred (renewal; Bouton \& Bolles, 1979). Another technique that can be used to restore the performance to an extinguished CS involves the reintroduction of the US prior to presentation of the extinguished CS (reinstatement; Pavlov, 1927, p. 62).

Previous studies by Kehoe and his associates using the rabbit nictitating membrane (NM) preparation have revealed what may be an additional technique for recovering the $\mathrm{CR}$ to an extinguished $\mathrm{CS}$, which has been denoted concurrent recovery. With this technique, a stimulus (CSA) from one modality (e.g., tone) is paired with the US (CSA-US) and is then extinguished (CSA-). In the next stage, another stimulus (CSB) from a different modality (e.g., light) is introduced and paired with the US

Preparation of this manuscript was supported by Australian Research Council Grant DP0344082. The authors thank Stephanie Dartnall for her assistance in the preparation of this manuscript. Correspondence should be sent to E. J. Kehoe, School of Psychology, University of New South Wales, Sydney, NSW 2052, Australia (e-mail: j.kehoe@unsw.edu.au).
(CSB-US). During CSB-US training, the original CSA is tested without reinforcement. As responding is acquired to CSB, responding to the original CSA recovers up to $75 \%$ of its original strength, despite its not having been reinforced since initial acquisition training (Kehoe, Horne, \& Macrae, 1995; Macrae \& Kehoe, 1999; Weidemann \& Kehoe, 2003).

Concurrent recovery does not appear to rely on spontaneous recovery or stimulus generalization. With regard to spontaneous recovery, after thoroughly extinguishing the CR to CSA, Weidemann and Kehoe (2003) tested the original CSA prior to the start of training with CSB. No responding to CSA appeared, thus eliminating spontaneous recovery as a contributor to the reappearance of responding to CSA. With regard to stimulus generalization from the CSB back to the original CSA, there is no evidence that NM responding generalizes across modalities, even at a subthreshold level. For example, Kehoe (1992) collated the results of several studies in which 126 rabbits first received training with CSA in one modality and then were given tests for generalization to CSB in a different modality. Another 117 rabbits that had not received the initial training were tested as controls. Both the trained and the control animals showed identical and negligible levels of responding on tests of CSB. Given the large sample size, there was more than adequate statistical power to detect even weak generalization. More recently, Macrae and Kehoe (1999) compared the three-stage concurrent recovery procedure (CSA-US/CSA-/CSB-US, test CSA) to two procedures for estimating cross-modal generalization. One was a reacquisition procedure (CSB-US/CSB-/CSB-US, test CSA), and the other was a rest control (-/-/CSB-US, test CSA). For these two 
control procedures, generalization from CSB was the only potential source of responding to CSA. In fact, neither control group showed more than a negligible level of responding to CSA, thus eliminating stimulus generalization as a key contributor to concurrent recovery.

The procedure for concurrent recovery bears a family resemblance to the procedures for renewal and reinstatement. Both of these procedures entail changing the context between extinction and the final testing stage for the original CS, either by changing the external background cues or by reintroducing the US and its presumed internal consequences. By the same token, concurrent recovery certainly entails reintroduction of the US, and, furthermore, the pairing of a novel CS with the US may act as a change in external context. For rabbit eyelid conditioning, however, there is as yet no evidence for either renewal or reinstatement. Rabbits do show some sensitivity to contextual manipulations (see Giftakis \& Tait, 1998; Hinson, 1982; Saladin \& Tait, 1986), but in the case of renewal, a search of the literature failed to reveal any manipulations of external background cues after extinction. In the case of reinstatement, Napier, Macrae, and Kehoe (1992) attempted to detect reinstatement after initial acquisition and extinction of a CS. Specifically, they compared responding to four CS-alone trials presented before four US-alone trials versus four CS-alone trials presented after the US trials. This comparison failed to reveal any significant changes in responding before versus after the US presentations. Responding to the four CS-alone trials after the US-alone trials yielded a response level of only 3\% CRs, which did not differ from that shown by naive animals.

Napier et al.'s (1992) failure to find US reinstatement may have been due to the limited number of US presentations. Evidence from unpaired extinction procedures in rabbit eyelid conditioning indicates that numerous US presentations during extinction training can elevate responding to the extinguishing CS (Frey \& Butler, 1977; but see Napier et al., 1992; Schreurs, Shi, Pineda, \& Buck, 2000). Similarly, the available hypotheses about reinstatement suggest that a larger number of US presentations may be necessary to induce the recovery of responding. If the US itself directly provides contextual cues that signal subsequent CS-US pairings (Capaldi, $1967,1994)$, then it may take more than four presentations at the start of the session to establish and sustain the appropriate internal context across subsequent CS presentations. In addition, reinstatement may occur because US presentations cause conditioning of external contextual stimuli (Bouton, 1988; Richardson, Duffield, Bailey, \& Westbrook, 1999), which then trigger the animal to retrieve the acquisition context rather than the extinction context. Given that the rabbit NM preparation requires numerous $\mathrm{CS}-\mathrm{US}$ presentations for $\mathrm{CR}$ acquisition to discrete CSs, more than four pairings of the US with the contextual cues may be needed in order to condition them. As an alternative to either direct contextual cuing by the US or context conditioning by the US, concurrent recovery may depend on pairings of the US with a discrete CS rather than with contextual stimuli, to retrieve the acquisition context.

In light of these hypotheses, the present experiments had two main purposes, which were complementary: (1) to determine whether or not an extended series of US-alone presentations would reinstate the CR to an extinguished CS as predicted if there is direct contextual cuing by the US and/or context conditioning by the US and (2) to determine whether pairings of the US with a new, discrete CS and the resulting CR acquisition are necessary for the reappearance of the CR to an extinguished CSA.

\section{EXPERIMENT 1}

In Experiment 1, we examined (1) whether the reintroduction of the US is sufficient to reinstate the CR to an extinguished CS and (2) whether any observed reinstatement is equal to the level of concurrent recovery of the CR to the extinguished CSA seen when the US is paired with a new stimulus in a different modality (i.e., $\mathrm{CSB}$ ). In Experiment 1, extinction of the CR to the original CSA was conducted using conventional CS-alone presentations as well as explicit unpairings of CSA and the US. The unpairings were conducted by extending the interval between the CS and the US from $250 \mathrm{msec}$ to an average of $30 \mathrm{sec}( \pm 5 \mathrm{sec})$, thus maintaining the sequence of stimulus presentations and their overall contingency (Rescorla, 1967).

Unpaired extinction, which retains the US, could diminish the level of reinstatement or concurrent recovery for the following reasons. Hypotheses of reinstatement generally assume that the US is a dominant part of the acquisition context. Hence, in CS-alone extinction, the absence of the US clearly distinguishes the extinction context from the acquisition context. The absence of the US during CS-alone extinction also protects whatever cue value it gained as a predictor of subsequent CS and/or US presentations during acquisition training (Capaldi, 1994; Frey \& Butler, 1977). In unpaired extinction, the presence of the US would increase the similarity between the extinction and acquisition contexts and also would allow for extinction of the cue value of the US. Consequently, the ability of the US by itself to retrieve the acquisition context and cause reinstatement and concurrent recovery would be reduced. However, if recovery of responding depends on there being new acquisition caused by pairings of the US with CSB, then concurrent recovery would still occur intact after unpaired extinction.

\section{Method}

Subjects. The subjects were 32 female albino rabbits (Oryctolagus cuniculus). On arrival from the breeding unit of the University of New South Wales, they were 70-80 days old and weighed approximately $1.5 \mathrm{~kg}$. All the rabbits were individually housed and had free access to food and water.

Apparatus. The apparatus and recording procedures for the NM response were modeled on those described by Gormezano (1966). 
During training, each subject was restrained in a Perspex box $(45 \times$ $14 \times 12 \mathrm{~cm}$ ). The rabbit was held in place by insertion of its head through an adjustable stock and by securing its ears to the front of the stock with a polyurethane foam-covered metal clamp. The rabbits were trained individually in one of eight sound-attenuating chambers. In each chamber, a speaker was mounted approximately $8 \mathrm{~cm}$ anterior to and $16 \mathrm{~cm}$ above the subject's head. The speaker delivered the auditory $\mathrm{CS}$, which was a $1000-\mathrm{Hz}, 88-\mathrm{dB}$ (sound pressure level, or SPL) tone of 250-msec duration. A constant background noise $(81 \mathrm{~dB}, \mathrm{SPL})$ was provided by a ventilating fan positioned at the rear of the conditioning chamber. Mounted on the stimulus panel $4 \mathrm{~cm}$ above the speaker was an 8 -W neon light that served as the houselight. A visual CS was provided by a $20-\mathrm{Hz}$ flashing of the houselight for $250 \mathrm{msec}$. The US was a $50-\mathrm{msec}, 3-$ $\mathrm{mA}, 50-\mathrm{Hz} \mathrm{AC}$ electric current delivered via 9-mm stainless steel Autoclip wound clips positioned $10 \mathrm{~mm}$ apart and $15 \mathrm{~mm}$ posterior to the dorsal canthus of the rabbit's right eye. The sequence and timing of stimulus events were controlled by an Apple II computer equipped with interfaces and software developed by Scandrett and Gormezano (1980).

To record the NM response, each rabbit wore a muzzle-like headset that fitted securely about the snout and supported a photoelectric transducer for detecting movements of the NM. A small tinned copper wire hook was attached to a silk loop sutured into the NM of the rabbit's right eye. The other end of the hook was connected to an L-shaped crank that operated the photoelectric transducer (Gormezano \& Gibbs, 1988). The signal from the phototransistor was amplified and transmitted to an analog-digital converter (10msec sample rate) installed in the computer.

Procedure. All the rabbits received 1 day of preparation, 2 days of recovery, 1 day of adaptation, and 11 days of training and testing. On the preparation day, hair surrounding the rabbit's right eye was clipped and a small loop of surgical silk (000 Dynex) was sutured into the NM of the rabbit's right eye using a local anaesthetic (proxymetacaine hydrochloride). The rabbits were returned to their home cages for 2 days of recovery following preparation. On the adaptation day, the rabbits were placed in the conditioning apparatus for $60 \mathrm{~min}$, but no stimuli were presented.

On the day following adaptation, the rabbits were randomly assigned to one of four groups $(n=8)$. In Stage 1, which lasted for 2 days, training was the same for all the groups. On each day, all the animals received 60 CSA-US pairings. For half of the animals in each group, CSA was the tone. For the other half, CSA was the light. The CSA-US interval (onset to onset) was $250 \mathrm{msec}$. The mean intertrial interval (ITI) was about $60 \mathrm{sec}$ (range, $50-70 \mathrm{sec}$ ).

In Stages 2 and 3, the four groups constituted a $2 \times 2$ factorial manipulation of two variables: (1) the type of extinction training in Stage 2 -namely, CS-alone presentations (E) versus explicitly unpaired presentations of the CS and US (U), and (2) the type of training in Stage 3-namely, cross-modal acquisition to a new stimulus in a new modality (CMA) versus reinstating presentations of the US alone (Reinstate). The resulting four groups were designated as Group E-CMA, Group U-CMA, Group E-Reinstate, and Group UReinstate. The design of this experiment as well as those of the subsequent experiments reported in this article are summarized in Table 1.

On each day in Stage 2, which lasted for 6 days, Groups E-CMA and $\mathrm{E}-$ Reinstate received $60 \mathrm{CSA}$-alone extinction trials per session at a mean ITI of $60 \mathrm{sec}$. Groups U-CMA and U-Reinstate received 60 explicitly unpaired presentations of CSA and the US per session, in which presentations of CSA and the US were spaced at approximately $30-\mathrm{sec}$ intervals. For Groups U-CMA and UReinstate, the mean ITI was about $30 \mathrm{sec}$ (range, 25-35 sec), and CSA and the US were effectively alternated.

On the first day of Stage 3, at the very beginning of the session, all the groups received two CSA-alone trials for assessment of spontaneous recovery. Thereafter, for the remaining 3 days, the training schedule for all four groups contained six 10-trial blocks.
Table 1

Experimental Designs

\begin{tabular}{llrll}
\hline Group Label & \multicolumn{1}{c}{ Stage 1 } & Stage 2 & Stage 3 & Stage 3 Tests \\
\hline \multicolumn{5}{c}{ Experiment 1 } \\
E-CMA & CSA-US & CSA- & CSB-US & CSA \\
U-CMA & CSA-US & CSA/US & CSB-US & CSA \\
E-Reinstate & CSA-US & CSA- & US & CSA \\
U-Reinstate & CSA-US & CSA/US & US & CSA \\
\multicolumn{5}{c}{ Experiment 2 } \\
Exp & CSA-US & CSA- & CSB-US & CSA, CSC \\
\multicolumn{5}{c}{ Experiment 3 } \\
0B + & CSA-US & CSA - & CSB-US & CSA \\
240B + & CSA-US, CSB-US CSA- & CSB-US & CSA \\
\hline
\end{tabular}

For Group E-CMA and Group U-CMA, each 10-trial block contained nine CSB-US pairings and one CSA-alone trial. For Group E-Reinstate and Group U-Reinstate, each 10-trial block contained nine US-alone trials and one CSA-alone trial.

Definition of response. A CR was defined as any extension of the NM greater than or equal to $0.5 \mathrm{~mm}$ that occurred following the onset of the CS but prior to its termination (Marshall-Goodell, Schreurs, \& Gormezano, 1982).

\section{Results}

Unless otherwise noted, orthogonal, planned contrasts were used to analyze the data and the rejection level was set according to a Type I error rate of .05 (Harris, 1994; O'Brien \& Kaiser, 1985). One animal in each of Groups E-CMA and U-Reinstate injured itself during adaptation and had to be removed from the experiment. Because the present experiments focused on recovery of responding in Stage 3, rigorous criteria were applied to ensure that each subject had shown both sufficient acquisition by the end of Stage $1(>50 \% \mathrm{CRs})$ and complete extinction by the end of Stage $2(<10 \%$ CRs). Two animals in Group E-CMA and 1 animal in Group U-Reinstate failed to show CR acquisition in Stage 1; their levels of responding across the last day of Stage 1 acquisition were less than $20 \%$ CRs. Accordingly, their data were excluded from the analysis and presentation of the results. Thus, Group E-CMA was reduced to 5 animals and Group U-Reinstate was reduced to 6 animals. Figure 1 depicts mean percent $\mathrm{CR}$ performance during the three stages of Experiment 1.

Stage 1: CR acquisition on CSA-US trials. Panel A of Figure 1 shows the mean percentage CRs for all four groups plotted across the two days of Stage 1. Each day is divided into six blocks of 10 trials. The curves show that all four groups rapidly acquired CRs to asymptotic levels exceeding 90\% ( $\pm 3 \% S E M)$. Statistical analysis yielded a significant linear trend across blocks $[F(1,23)=152.18$, $p<.01]$. The acquisition curves of the four groups appear almost identical; any apparent differences between them failed to attain statistical significance [largest $F(1,23)=$ $1.48, p>.10]$.

Stage 2: Extinction of CRs on CSA trials. Panel B of Figure 1 shows the mean percentage CRs in 10-trial blocks across the 6 days of Stage 2. All four groups 


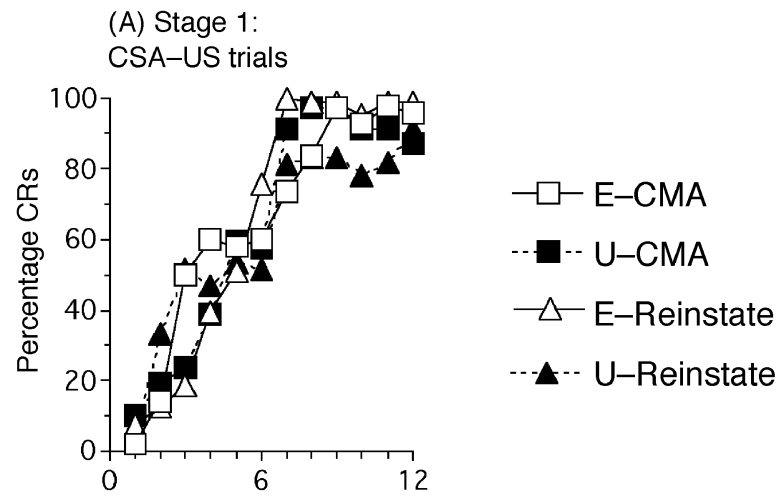

(B) Stage 2:

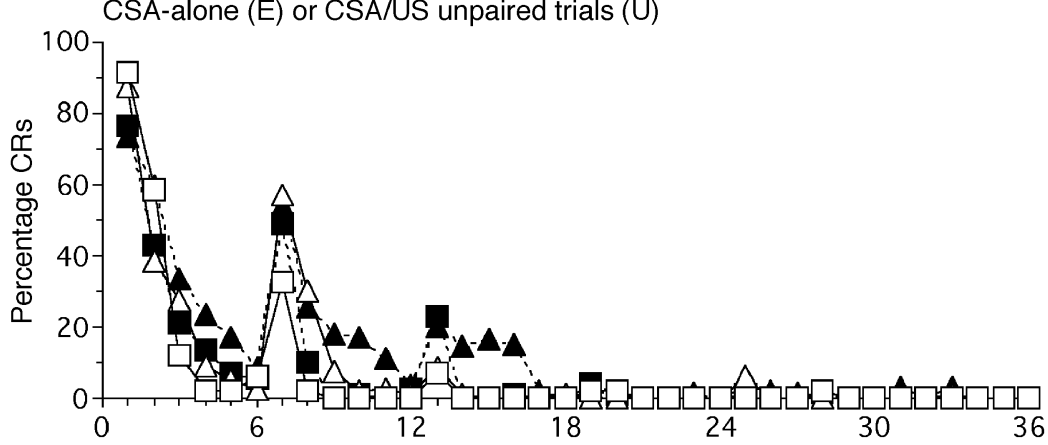

(C) Stage 3:

CSB-US trials

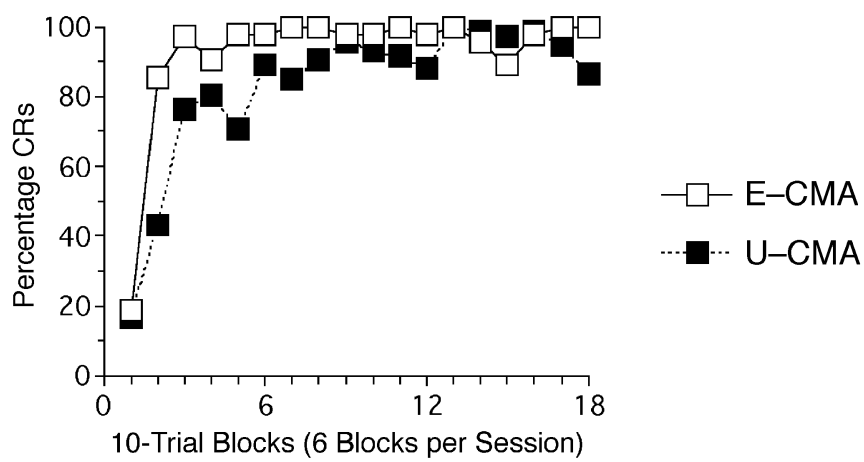

Figure 1. Percentage conditioned responses (CRs) of Groups E-CMA, U-CMA, E-Reinstate, and U-Reinstate as a function of 10-trial blocks in Stages 1, 2, and 3 of Experiment 1. Panel A shows acquisition of responding on CSA-US trials in Stage 1. Panel B shows the extinction of responding on CSA - trials in Stage 2. Panel C shows acquisition of responding on CSB-US trials in Stage 3 in Groups E-CMA and U-CMA.

showed a general decline in responding across blocks, from approximately $80 \% \mathrm{CRs}( \pm 5.4 \% S E M)$ in the first block to under $1 \%$ CRs $( \pm 0 \% S E M)$ in the last block. Statistical analysis yielded a significant linear trend across days $[F(1,23)=55.79, p<.01]$. The extinction curves of the four groups appear to be almost identical; any apparent differences between them failed to attain statistical significance [largest $F(1,23)=1.31$ ]. There appeared to be more spontaneous recovery at the beginning of Day 3 of extinction in the unpaired extinction groups than in the
CS-alone extinction groups. However, a post hoc analysis of the difference between the unpaired extinction groups and the CS-alone extinction groups on the first block of trials on Day 3 of Stage 2 failed to reach statistical significance $[F(1,23)=1.95, p>.10]$.

Stage 3: CR acquisition on CSB-US trials. Panel C of Figure 1 shows mean percentage CRs in Groups E-CMA and U-CMA in 10-trial blocks across the 18 blocks of CSB-US pairings in Stage 3. (The percentage CRs for each block were based on the 9 CSB-US trials in 


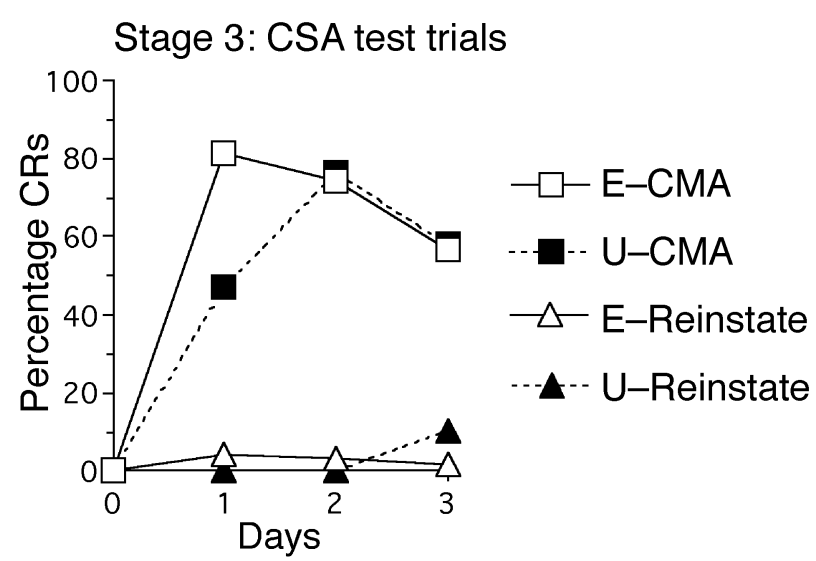

Figure 2. Percentage conditioned responses (CRs) on test trials of CSA in Groups E-CMA, U-CMA, E-Reinstate, and $\mathrm{U}$-Reinstate. The first data point represents responding prior to the beginning of Stage 3, and subsequent data points are a function of days in Stage 3.

each block; the 10th trial in each block was a test trial of CSA.) The curves show that both groups acquired CRs to asymptotic levels exceeding $90 \%( \pm 5 \%$ SEM $)$ by the end of the third day. Although Group E-CMA appeared to show slightly faster CR acquisition than Group U-CMA, this difference was not statistically significant in either overall comparisons between the groups or interactions with trial blocks [largest $F(1,11)=4.46, p>.05$ ].

Stage 3: Recovery of CRs on CSA test trials. Figure 2 shows the results of the test trials with CSA in Stage 3 of Experiment 1 . As can be seen in Figure 2, testing at the beginning of Stage 3 revealed no responding in any of the groups, thus demonstrating that there was no spontaneous recovery to CSA at the beginning of Stage 3 . As $\mathrm{CR}$ acquisition proceeded to CSB in Groups E-CMA and U-CMA, both groups recovered responding to CSA. In fact, across the 3 days of Stage 3, the mean CR likelihood on CSA test trials in both cross-modal acquisition groups reached average levels of over $60 \%( \pm 8 \% S E M)$. In contrast, presentations of the US alone failed to induce any discernible reinstatement of responding to CSA. Groups E-Reinstate and U-Reinstate showed mean levels of less than $5 \%$ CRs to CSA $( \pm 2 \% S E M)$ over the 3 days of Stage 3. This level was indistinguishable from baseline levels of responding in the NM preparation (Gormezano, Kehoe, \& Marshall, 1983).

Statistical analyses confirmed the apparent group differences in responding to CSA. There was a main effect for the groups given cross-modal acquisition training versus the groups given presentation of the US alone $[F(1,23)=49.04, p<.01]$. There was no significant main effect for the type of extinction training the animals received $(F<1)$. The interaction between these factors was also nonsignificant $(F<1)$. Group E-CMA appeared to achieve a higher level of recovery than Group U-CMA on Day 1 of Stage 3. A post hoc analysis failed to confirm this apparent difference $[F(1,11)=3.13, p>.05]$.

\section{Discussion}

Experiment 1 resulted in two key findings. The main finding was that the reintroduction of CS-US pairings in Stage 3, albeit to a CS in a different modality than that of the original CS, resulted in strong recovery of responding to the original CS. This finding confirms previous demonstrations of concurrent recovery in the rabbit NM preparation (Kehoe et al., 1995; Macrae \& Kehoe, 1999). In addition to confirming previous demonstrations, which used conventional, CS-alone extinction, the present experiment showed that the recovery of responding to the original CS was robust in the face of an unpaired extinction procedure. In fact, any apparent diminution of concurrent recovery after unpaired extinction was transient and failed to reach statistical significance. The second finding was that the reintroduction of the US alone in Stage 3 failed to result in any discernible reinstatement of responding to the original CS, thus suggesting that concurrent recovery relies on pairings of the US with the new CS.

The two key findings indicate that concurrent recovery of responding to the original CS during cross-modal acquisition is not a species of reinstatement. Accordingly, several accounts of reinstatement do not apply to concurrent recovery. First, if recovery of responding is a result of the US's acting as part of the context that combines with the CS to retrieve the CR, then reintroduction of the US alone should have resulted in recovery of responding. Second, and similarly, if the US helps distinguish between the extinction context and the acquisition context, either directly or indirectly through the conditioning of contextual cues, then again recovery should have occurred after US-alone presentations. Third, if recovery is a result of the reactivation of a US representation, then reintroduction of the US should have resulted in the progressive recovery of responding to the test CS presentations (Rescorla \& Heth, 1975).

The strong result of the present experiment is that recovery of responding to the original CS appeared only when there was paired acquisition training with a new CS. This finding suggests that concurrent recovery is mediated by new excitatory learning. A similar result has been obtained in experiments in which the "reactivation" of fear conditioning in rats was examined. For example, Lashley, Richardson, and Riccio (1987) found that rats that were subjected to fear conditioning of a context and then extinguished to the context showed recovery of conditioned responding to the original context when they had been shocked in a new context before being tested. Thus, pairing a new context with the US brings about recovery of responding to the original extinguished context in the same way that pairing a new CS with the US brings about recovery of responding to the original extinguished CS.

Richardson et al. (1999) have provided support for the hypothesis that recovery of fear conditioning is mediated by new learning. After acquisition and extinction training in one context, rats were presented with the US im- 
mediately after being placed in a new context. That is, the rats were presented with virtually a simultaneous context-US relation, which would not be highly conducive to learning. In fact, the rats displayed little fear of the new context and failed to show recovery of responding when placed back in the original context. In contrast, rats that received the US in the new context after a 30 -sec delay acquired substantial fear of that context and also a substantial recovery of responding to the original context. Therefore, recovery of fear conditioning to an extinguished context was not due to presentation of the US and/or the new context but, rather, to the acquisition of the new context-US association.

If new learning mediates concurrent recovery, then the amount of concurrent recovery should be correlated with $\mathrm{CR}$ acquisition to the new orthogonal CS. In the present experiment, there is some evidence of such a relationship. Specifically, if one compares Figures 1 and 2, it can be seen that in Stage 3 both cross-modal acquisition to CSB and concurrent recovery to CSA were greater after CS-alone extinction than after explicitly unpaired extinction. We also computed a correlation coefficient between the CR percentages to CSB and CSA, using the data from the first day of Stage 3 for each of the rabbits in the cross-modal acquisition groups $(N=13)$. There was a significant positive correlation of $.55(p<.05)$.

Although there is evidence to suggest that rabbits given noncontingent US exposures do associate the US with the context (Hinson, 1982), the temporal relationship between the contextual cues and the US are such that the context does not come to evoke discrete eyelid CRs (Macrae \& Kehoe, 1995; Weidemann \& Kehoe, 1997). In the rabbit NM preparation, a CS-US interval of $100-5,000 \mathrm{msec}$ is necessary for the reliable acquisition of eyelid CRs (Kehoe \& Macrae, 2002). Thus, new learning of a discrete eyelid CR during CSB-US pairings is necessary for the recovery of discrete eyelid CRs to the extinguished CS.

\section{EXPERIMENT 2}

Experiment 1 provided evidence that concurrent recovery is mediated by new, excitatory learning to another discrete CS rather than by reinstatement through USalone presentations. One obvious mechanism through which new, excitatory learning could result in responding to the trained and extinguished CS is through generalization from CSB to the trained and extinguished CSA. However, as was mentioned in the introduction, previous experiments in the rabbit NM preparation have demonstrated that training a CS in one modality results in negligible levels of responding to a test stimulus in another modality, barely above that of baseline responding (Kehoe, 1992; Macrae \& Kehoe, 1999). Nevertheless, a withinsubjects assessment of cross-modal generalization during a concurrent recovery procedure has never been conducted. Reinforced training of two stimuli in two different modalities might induce widespread cross-modal stimulus generalization.
In order to assess cross-modal generalization on a within-subjects basis, it was necessary to use a stimulus in a third modality - specifically, a vibrotactile stimulus. Hence, in Experiment 2 subjects were trained with a stimulus in one modality (CSA) and were then extinguished to that stimulus before being trained with a new stimulus from a different modality (CSB). During this training with $\mathrm{CSB}$, nonreinforced test trials of CSA and a novel stimulus from a third modality (CSC) were presented.

\section{Method \\ Subjects. The subjects were 8 female albino rabbits.}

Apparatus and Procedure. Unless otherwise mentioned, the apparatus and procedure were identical to those of Experiment 1 . The CSs were a $1000-\mathrm{Hz}, 88-\mathrm{dB}$ (SPL) tone, a $20-\mathrm{Hz}$ flashing of the houselight, and a $27-\mathrm{Hz}$ vibrotactile stimulation to the back of the animal. All of the CSs were $400 \mathrm{msec}$ in duration throughout all three stages of the experiment. A constant background noise throughout the experiment ( $83 \mathrm{db}, \mathrm{SPL})$ was provided by a white noise generator and each chamber's ventilating fan. The white noise was added to the already existing background noise in order to mask the small auditory component generated by the vibrotactile CS.

The vibration for the vibrotactile CS was provided by a low-speed/ low-voltage DC motor with an off-center brass weight attached to its rotating shaft. The motor was shielded on two sides with a lightweight aluminum casing attached to the motor with Araldite. The casing surrounding the motor was attached to a Velcro strap with contact adhesive. The Velcro strap was wrapped around the rabbit in such a way that the motor was approximately $10 \mathrm{~cm}$ from the animal's head and directly above its spine. The aluminum casing surrounding the motor was in direct contact with the animal's skin.

All the rabbits received 1 day of preparation, 1 day of adaptation, and 14 days of training. On the preparation day, a $2 \times 4-\mathrm{cm}$ rectangle of hair was shaved from the center of each animal's back. On the adaptation day, the rabbits were placed in the conditioning apparatus for $60 \mathrm{~min}$, but neither a CS nor a US was presented.

Stage 1 training lasted for 4 days, during which all the animals received 60 CSA-US pairings per day. For half of the animals, CSA was the tone, and for the other half CSA was the vibrotactile stimulus. The mean ITI was $60 \mathrm{sec}$ (range, $50-70 \mathrm{sec}$ ) throughout Stage 1.

Stage 2 training lasted for 6 days. All the animals received 60 CSA-alone trials per day.

In Stage 3, which lasted for 4 days, all the animals received 60 training trials of the light stimulus paired with the US (CSB-US). On the first day of Stage 3, prior to the beginning of CSB-US trials, all the animals received 2 test trials of CSA and CSC, in which CSC was a novel, cross-modal stimulus. For those animals for which CSA was the tone, CSC was the vibrotactile stimulus, and for those animals for which CSA was the vibrotactile stimulus CSC was the tone. Subsequently, on each day of training, all the animals received $60 \mathrm{CSB}-\mathrm{US}$ pairings and 3 test trials each of CSA and CSC. Each block of 22 trials had 20 CSB-US pairings and 1 test trial each of CSA and CSC.

\section{Results and Discussion}

Unless otherwise noted, orthogonal, planned contrasts were used to analyze the data and the rejection level was set according to a Type I error rate of .05. All 8 animals achieved the criteria for acquisition and extinction and, hence, their data were included in the results. Figure 3 depicts CR performance during the three stages of Experiment 2 .

Stage 1: CR acquisition on CSA-US trials. Panel A of Figure 3 shows the mean percentage CRs for the 4 days 

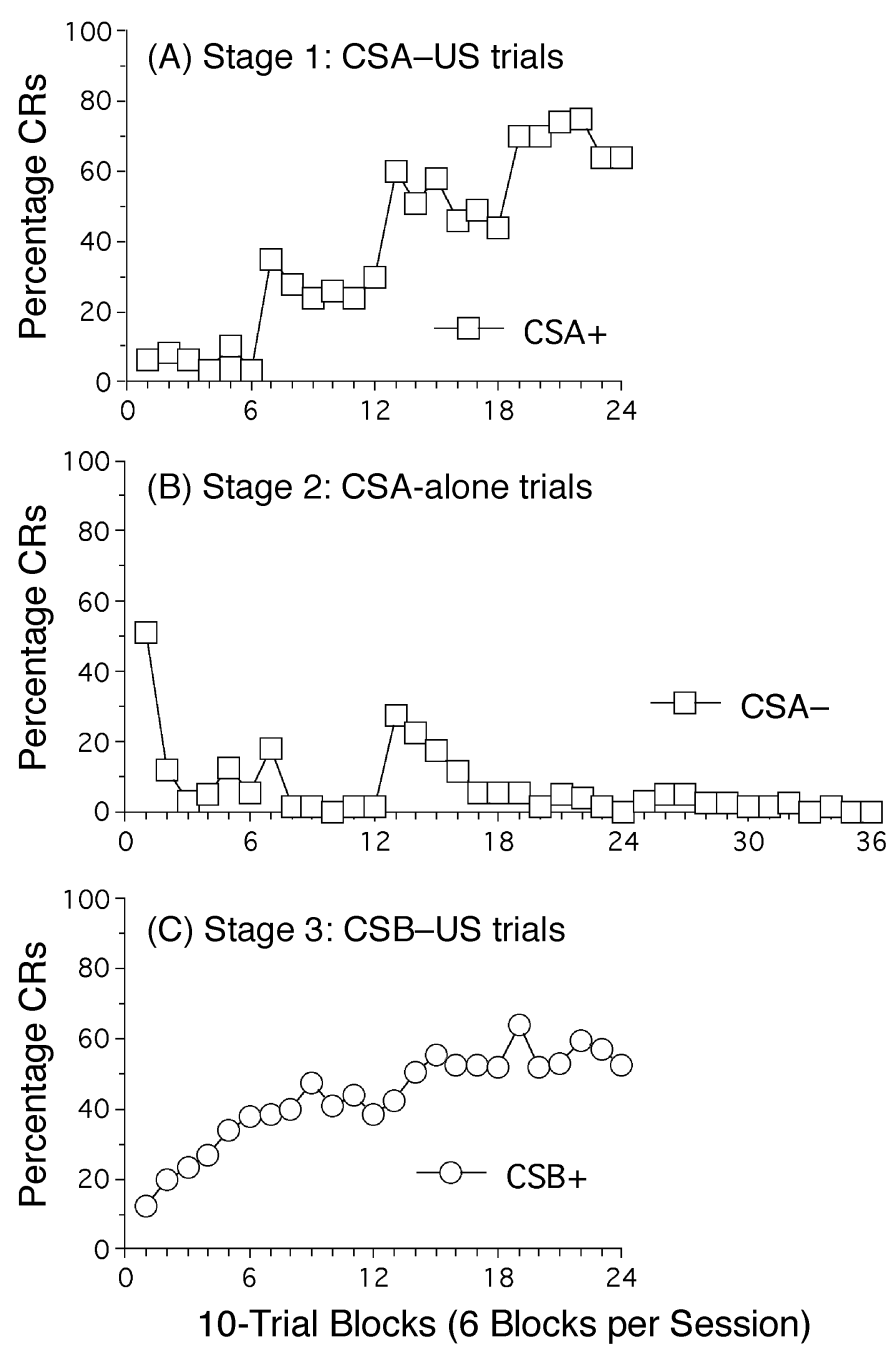

Figure 3. Percentage conditioned responses (CRs) as a function of 10trial blocks in Stages 1, 2, and 3 of Experiment 2. Panel A shows the acquisition of responding on CSA-US trials in Stage 1. Panel B shows the extinction of responding on $\mathrm{CSA}-$ trials in Stage 2. Panel $\mathrm{C}$ shows the acquisition of responding on CSB-US trials in Stage 3.

of CSA-US training in Stage 1. Each day is divided into six blocks of 10 CSA-US trials. The curve shows that CRs were acquired to asymptotic levels of about $70 \%$ $( \pm 10 \% S E M)$. Statistical analysis yielded a significant linear trend across days $[F(1,7)=68.95, p<.01]$.

Stage 2: Extinction of CRs on CSA-alone trials. Panel B of Figure 3 shows the mean percentage CRs on CSA-alone trials plotted in 10-trial blocks across the 6 days of Stage 2. There was a general decline in responding across blocks from approximately $50 \%$ CRs $( \pm 10 \%$ $S E M)$ in the first block to under $2 \%$ CRs $( \pm 0 \% S E M)$ in the last block. Statistical analysis yielded a significant linear trend across days $[F(1,7)=16.22, p<.01]$.

Stage 3: CR acquisition on CSB-US trials. Panel C of Figure 3 shows the mean percentage CRs on CSB-US trials plotted in 10-trial blocks across the 4 days of Stage 3 . As can be seen from panel C, initial acquisition to CSB was rapid. On the first day of Stage 3, the mean CR likelihood to CSB reached a level of $38 \%( \pm 11 \%$ SEM). By the end of Stage 3, responding rose to asymptotic levels of around $60 \%$ CRs $( \pm 11 \%$ SEM $)$. The asymptotic levels of responding to the light CS (CSB) were somewhat lower than have previously been seen in the rabbit NM preparation. This is due to the fact that 2 animals failed to acquire CRs to CSB. Despite this, statistical analysis yielded a significant linear trend across days $[F(1,7)=$ $8.64, p<.05]$.

Stage 3: Recovery of CRs on CSA and CSC test trials. Figure 4 shows responding on CSA-alone and CSCalone test trials across the 4 days of Stage 3. As can be 


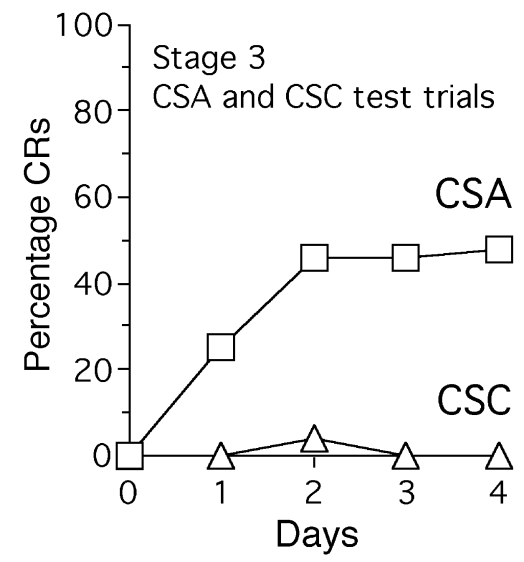

Figure 4. Percentage conditioned responses (CRs) on test trials of CSA and CSC in Stage 3 of Experiment 2. The first data point, on Day 0, represents responding prior to the beginning of CSB-US trials, and subsequent data points are a function of days in Stage 3.

seen in Figure 4, both CSA and CSC elicited no responding at the beginning of Stage 3. As CR acquisition proceeded to CSB, the animals showed substantial recovery of responding to the trained and extinguished CSA. In fact, across the 4 days of Stage 3, the mean CR likelihood on CSA-alone trials was approximately $42 \%( \pm 11 \%$ $S E M)$. In contrast, the animals showed virtually no responding to the novel, cross-modal stimulus CSC. The mean CR likelihood on CSC-alone trials was less than 5\% $( \pm 4 \% S E M)$ over the 4 days of Stage 3 . This level was indistinguishable from baseline levels of responding in the NM preparation (Gormezano et al., 1983).

Statistical analyses confirmed the apparent differences. There was a main effect for stimuli [CSA vs. CSC; $F(1,7)=14.38, p<.01]$ as well as a significant linear trend across days $[F(1,7)=9.87, p<.05]$. In addition, there was a significant interaction between the main effect for stimuli (CSA vs. CSC) and the linear trend across days $[F(1,7)=9.87, p<.05]$. When those animals that failed to condition to CSB during Stage 3 were removed from the analysis, the mean CR likelihood on CSA-alone trials rose to approximately $55 \%$ CRs $( \pm 10 \% S E M)$ across the 4 days of Stage 3. An examination of the subject-by-subject data revealed that those animals that failed to condition to CSB also failed to show any recovery of responding to CSA in Stage 3. This result is consistent with the hypothesis that concurrent recovery is mediated by new, excitatory learning.

Thus, Experiment 2, using a within-subjects design, demonstrated that concurrent recovery is specific to a stimulus that has been trained and extinguished and that training with CSB does not elevate responding to a novel, cross-modal stimulus. These results provide converging evidence with the results of Macrae and Kehoe (1999) that concurrent recovery is not the result of cross-modal generalization.

\section{EXPERIMENT 3}

Experiments 1 and 2 indicated that concurrent recovery is mediated by new, excitatory learning. To further test this hypothesis, in Experiment 3 we examined whether CSBUS pairings in Stage 1, prior to the extinction of CSA in Stage 2, would decrease the ability of CSB-US pairings in Stage 3 to induce recovery of responding to CSA. Presumably, the CSB-US pairings in Stage 1 would endow CSB with considerable excitatory strength, and because of this existing excitatory strength, subsequent CSB-US pairings in Stage 3 would be less able to increase excitatory strength of CSB. If concurrent recovery is mediated by new learning, this limitation in the acquisition of additional excitatory strength to CSB would also limit the amount of recovery to CSA during Stage 3 . In contrast, if concurrent recovery is due to the postextinction reintroduction of paired trials, then CSB-US pairings in Stage 1 should not affect the strength of concurrent recovery.

In Experiment 3, we also sought to examine whether the presentation of CSB in the absence of the US would precipitate recovery of responding to the trained and extinguished CSA. Any recovery of responding to CSA as a result of the introduction of CSB was assessed at the start of the first session of Stage 3 by a set of three nonreinforced presentations of CSA directly following three nonreinforced presentations of CSB.

\section{Method}

Subjects. The subjects were 16 female albino rabbits.

Apparatus and Procedure. Unless otherwise mentioned, the apparatus and procedure were identical to those of Experiment 1. On the third day following adaptation, the rabbits were randomly assigned to one of two groups designated Group $0 \mathrm{~B}+(n=8)$ and Group $240 \mathrm{~B}+(n=8)$ according to the number of CSB-US pairings they received in Stage 1B. Stage 1 lasted for 8 days. In Stage 1A, which lasted for 4 days, all the animals received 60 CSA-US pairings per day. In Stage 1B, which also lasted for 4 days, the animals in Group 240B + received $60 \mathrm{CSB}-\mathrm{US}$ pairings per day. The animals in Group $0 \mathrm{~B}+$ were placed in the conditioning chamber but were not presented with either CSB or the US. For half of the animals in each group, CSA was the tone and CSB was the light. For the other half of the animals, this assignment was reversed.

In Stage 2, which lasted for 6 days, training was the same for both groups. The animals in both groups received $60 \mathrm{CSA}$-alone extinction trials per day.

Stage 3, which lasted for 4 days, was the same for both groups. On the first day of Stage 3, at the very beginning of the session, three CSB-alone test trials followed by $3 \mathrm{CSA}$-alone test trials were presented. Subsequently, all the animals received $60 \mathrm{CSB}-\mathrm{US}$ trials and 6 CSA-alone test trials per day. Thereafter, a CSA-alone trial occurred after every 10th CSB-US trial.

\section{Results}

Unless otherwise noted, orthogonal, planned contrasts were used to analyze the data and the rejection level was set according to a Type I error rate of .05. One animal in Group 240B + failed to meet the criterion for extinction; it persisted in responding at levels of more than $25 \%$ CRs throughout all 6 days of extinction. Accordingly, its data 
were excluded from the presentation of the results. Thus, Group 240B + was reduced to 7 animals. Figure 5 depicts CR performance during the three stages of Experiment 3.

Stage 1A: CR acquisition on CSA-US trials. Panel A of Figure 5 shows the mean percentage of CRs for both groups plotted across the 4 days of CSA-US training in Stage 1. Each day is divided into six 10-trial blocks. The curves show that both groups acquired CRs, with responding averaging $63 \%$ CRs $( \pm 13 \% S E M)$ on the last day of CSA-US training. Statistical analysis yielded a significant linear trend across blocks $[F(1,13)=39.01$, $p<.01]$. The acquisition curves of the two groups were similar; any differences in either overall comparisons between the groups or interactions with trial blocks failed to attain statistical significance $(F \mathrm{~s}<1)$.

Stage 1B: CR acquisition on CSB-US trials. Panel B of Figure 5 shows the mean percentage of CRs for Group $240 \mathrm{~B}+$ plotted across the 4 days of CSB-US training in Stage 1. Each day is divided into six 10-trial blocks. As is apparent from panel B, Group 240B + rapidly acquired CRs to CSB, with levels of responding averaging over $80 \%$ CRs $( \pm 15 \%$ SEM) on the last day of CSB-US training. Statistical analysis yielded a significant linear trend across blocks $[F(1,6)=11.89, p<.05]$.

Stage 2: Extinction of CRs on CSA-alone trials. Panel C of Figure 5 shows the mean percentage of CRs to CSA during extinction plotted across the 6 days of Stage 2. Each day is divided into six blocks of 10 CSAalone trials. Inasmuch as initial acquisition to CSA in Stage $1 \mathrm{~A}$ reached only modest levels $(63 \% \mathrm{CRs})$, resistance to extinction was weak. On the very first CSA presentation in Stage 2, 8 of the 15 rabbits (53\%) showed a $\mathrm{CR}$, a level that approximated the level at the end of Stage 1A. Thereafter, responding dropped dramatically within the first block of 10 trials. Specifically, across the first block of extinction trials, Group 240B+ showed a mean of $35 \%$ CRs $( \pm 12 \% S E M)$ and Group $0 \mathrm{~B}+$ showed a mean of $15 \%$ CRs $( \pm 7 \%$ SEM $)$. The apparent difference between Group 0B + and Group 240B + approached but failed to reach the declared level of statistical significance $[F(1,13)=4.60, p<.10]$.

Stage 3: CR acquisition on CSB-US trials. Panel D of Figure 5 shows the mean percentage of CRs during CSB-US training plotted across the 4 days of Stage 3 . The first data point at Trial Block 0 represents responding during the initial CSB test trials. Subsequently, each day is divided into six blocks of 10 trials. As may be apparent, responding to CSB in Group 240B + had almost entirely disappeared between the end of Stage 1B and the start of Stage 3. This decrease in responding was statistically significant $[F(1,6)=25.70, p<.05]$. Groups $240 \mathrm{~B}+$ and $0 \mathrm{~B}+$ showed mean levels of $5 \% \mathrm{CRs}( \pm 4 \% S E M)$ and $0 \%$ CRs $( \pm 0 \% S E M)$, respectively $[F(1,13)=1.16, p>.10]$. Once CSB-US training began, Group 240B $+(M=67 \%$ CRs, $\pm 7 \% S E M$ ) initially showed higher responding than Group 0B $+[M=22 \%$ CRs, $\pm 13 \% \operatorname{SEM} ; F(1,13)=$ $7.23, p<.05]$. By the third day of Stage 3, both groups had acquired CRs to a level of $80 \%( \pm 20 \%$ SEM). The difference in the learning curves between Group 240B+ and Group $0 \mathrm{~B}+$ was confirmed by a significant interaction between the groups and their linear trends across blocks of trials $[F(1,13)=8.54, p<.05]$.

Stage 3: Recovery of CRs on CSA test trials. Figure 6 shows the results of CSA test trials across the 4 days of Stage 3. The first data point, on Day 0, represents responding to the three CSA test trials presented after the three initial CSB test trials at the beginning of Stage 3. As can be seen from Figure 6, initial testing revealed no responding to CSA in either of the groups. After CSB-US pairings were commenced, both groups recovered some responding to CSA. A comparison of responding to CSA before and after CSB-US pairings commenced confirmed this apparent recovery of responding $[F(1,13)=21.88$, $p<.01]$.

Although both groups recovered responding to CSA, they differed in their levels of responding. Specifically, on the first day of Stage 3, Group 0B + showed a level of $52 \%$ CRs $( \pm 13 \%$ SEM $)$ whereas Group $240 \mathrm{~B}+$ showed a much lower level of only $24 \%$ CRs $( \pm 13 \%$ SEM). Examination of the subject-by-subject data reveals the same pattern. In Group $0 \mathrm{~B}+, 7$ of the 8 animals showed at least one CR to CSA. In contrast, in Group 240B + only 3 of the 7 animals showed at least one CR to CSA. A statistical comparison confirmed the main effect for group in responding to CSA $[F(1,13)=5.45, p<.05]$. In addition, the difference between groups in the level of responding to CSA before and after CSB-US pairings commenced was confirmed by a significant interaction between groups and days $[F(1,13)=5.45, p<.05]$.

\section{Discussion}

Experiment 3 resulted in three main findings. The first, which replicated the findings of Experiments 1 and 2 , was that the introduction of CSB-US pairings in Stage 3 resulted in the recovery of responding to CSA. The second main finding was that the CSB-US pairings in Stage 1, prior to the extinction of CSA in Stage 2, reduced the recovery of responding to CSA during the subsequent CSB-US presentations in Stage 3. The third main finding was that the extinction of responding to CSA in Stage 2 resulted in the disappearance of responding to CSB in Group 240B +, in which responding to CSB had been well established at the end of Stage 1B.

With regard to the first main finding, the present experiment not only confirms the concurrent recovery seen in previous experiments but also adds to the evidence that concurrent recovery depends on CSB-US pairings. Whereas Experiment 1 ruled out US-alone presentations as sufficient to reinstate responding to CSA, the present experiment ruled out CSB presentations as sufficient to renew responding to CSA. That is, the tests of CSA in Stage 3 after nonreinforced presentations of CSB failed to produce responding to CSA in either group in Experiment 3. 

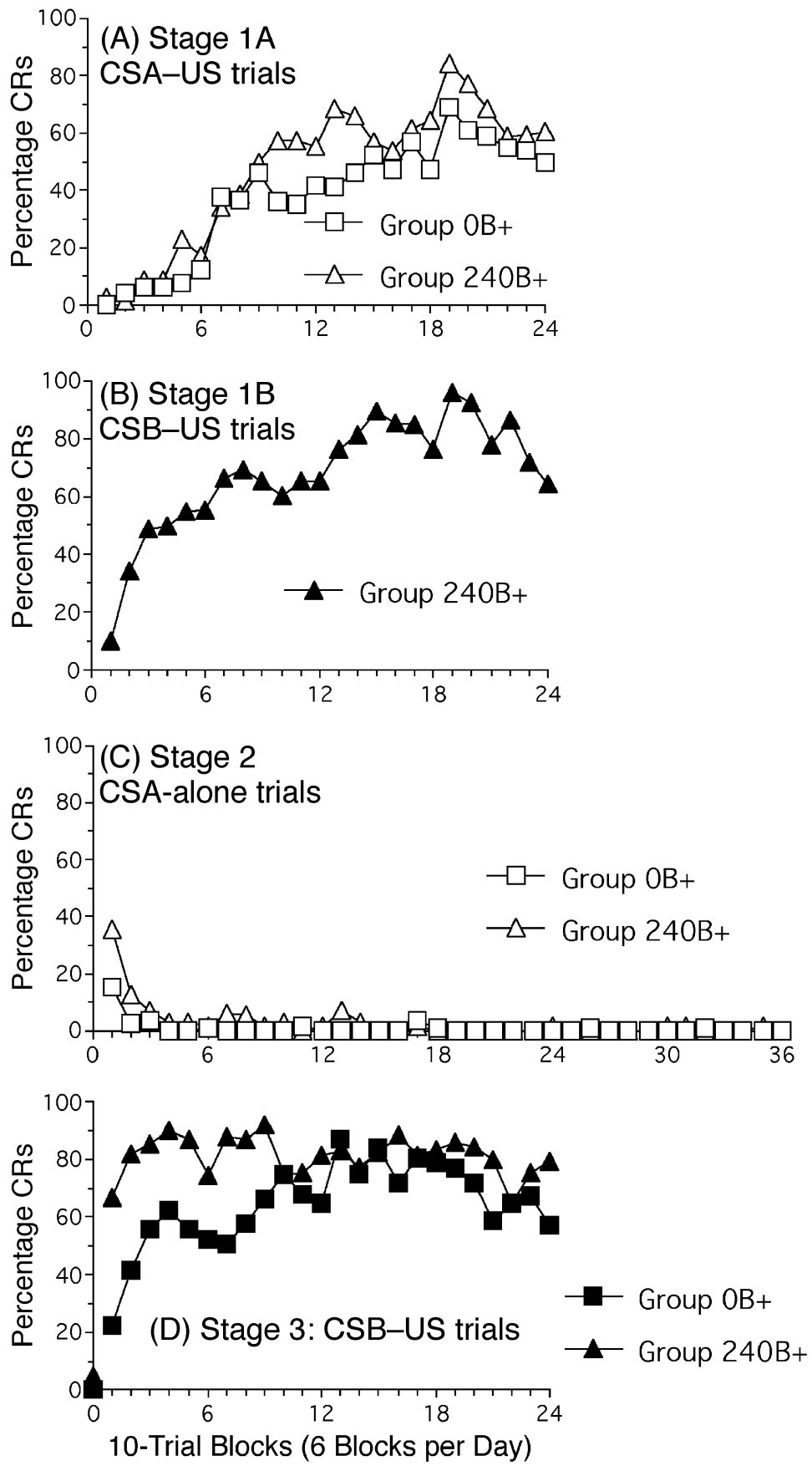

Figure 5. Percentage conditioned responses (CRs) of Group 0B + and Group 240B + as a function of 10-trial blocks in Stages 1, 2, and 3 of Experiment 3. Panel A shows the acquisition of responding on CSA-US trials in Stage 1A. Panel B shows the acquisition of responding on CSB-US trials in Group 240B + in Stage 1B. Panel $\mathrm{C}$ shows the extinction of responding on $\mathrm{CSA}-$ trials in Stage 2. Panel D shows the acquisition of responding on CSB-US trials in Stage 3. The first data point, on Day 0 , represents the level of responding on the three nonreinforced test trials prior to the beginning of paired training. Subsequent data points represent the levels of responding after the commencement of CSB-US paired trials, as a function of 10-trial blocks. 


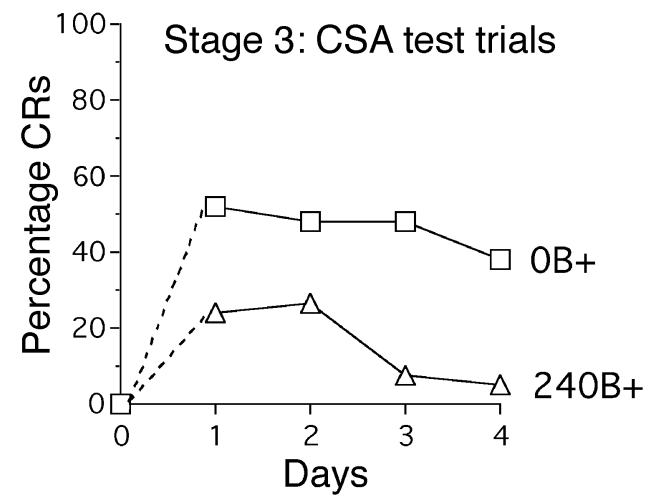

Figure 6. Percentage conditioned responses (CRs) on test trials of CSA in Groups $0 B+$ and $240 B+$. The first data point, on Day 0, represents the level of responding after the three CSBalone test trials, at the beginning of Stage 3. Subsequent data points represent the levels of responding averaged across the six test trials on each day of Stage 3.

The second main finding - namely, the significant reduction of concurrent recovery in Group $240 \mathrm{~B}+$ - is broadly consistent with the hypothesis that concurrent recovery depends on new, excitatory learning during the CSB-US pairings in Stage 3 and not just on the occurrence of CSB-US pairings per se. Support for this conclusion, however, would have been even stronger had the extinction training for CSA in Stage 2 not also abolished responding to CSB in Group 240B +. The secondary extinction of responding to CSB leaves open the possibility that concurrent recovery depends at least partly on a performance factor. That is, any increase in responding to CSB in Stage 3, whether it be original acquisition as in Group 0B + or reacquisition as in Group 240B +, may be sufficient to cause concurrent recovery to CSA. This point brings us to the third main finding: the secondary extinction of responding to CSB in Group 240B + .

The tests of CSB at the beginning of Stage 3 revealed an almost complete loss of responding to CSB between the end of CSB-US training in Stage 1B and the beginning of Stage 3 in Group 240B +. The loss of responding to CSB could not be attributed to any extinctive effects of the CSB-alone presentations. There remains the possibility that retention losses and/or nonreinforced exposures to the conditioning context during the 6 days of Stage 2 contributed to the loss of responding to CSB. With regard to retention losses, a 6-day interval is almost certainly too short. Retention in home cages for 90 days or more is needed to produce discernible retention losses in the rabbit NM preparation (Schreurs, 1993, 1998). With regard to exposure to the conditioning context, there is some previous evidence that it could have exerted an extinctive effect (Weidemann \& Kehoe, 2003, Experiment 3). In the present results, there is also evidence of context extinction. Specifically, Group 0B+received apparatus exposure during Stage 1B after it had been trained with CSA in Stage 1A. When extinction training with CSA was started in Stage 2, Group 0B+ showed a significant loss of responding relative to its performance at the end of Stage 1A. At this point, the safest conclusion is that the loss of responding to CSB seen in Group 240B + reflected a combination of context extinction based on apparatus exposure plus secondary extinction arising from CSA-alone presentations.

\section{GENERAL DISCUSSION}

The present experiments in the rabbit NM preparation resulted in four main findings. First, following training and extinction with CSA, the introduction of CSB-US pairings resulted in strong recovery of responding to CSA even when the US was retained during the extinction of CSA in an explicitly unpaired procedure. Second, this recovery was attributable to the CSB-US pairings, because the reintroduction of the US alone failed to result in any discernable reinstatement of responding to CSA. Third, concurrent recovery was specific to a CS that had been trained and extinguished and was not the result of cross-modal generalization. Fourth, a large number of CSB-US pairings in Stage 1 reduced the amount of recovery to CSA during subsequent CSB-US trials.

The results of the present experiments add to the evidence that a substantial portion of original learning is retained during extinction. On the theoretical front, there is an increasing number of identified mechanisms that could contribute to the protection and recovery of original learning after extinction (Kehoe \& White, 2002; Robbins, 1990). Conversely, no single theory can explain the full pattern of findings for extinction and recovery. Consequently, in the remainder of this discussion we will describe and evaluate the main mechanisms proposed for the restoration of responding after extinction - namely, (1) reintroduction of the context of acquisition, (2) changes in the relative associative strengths of the CS and its context, (3) changes in the expression of the residual excitatory associations, and (4) changes in the excitatory associations.

\section{Reintroduction of the Acquisition Context}

All extinction procedures involve changes in the objective experimental situation, including the omission of the US in conventional extinction or a change in the temporal relationship between the CS and the US, as in the explicitly unpaired procedure. Contextual control theories capitalize on these changes to explain both extinction and recovery from extinction. In particular, Bouton (1994) proposed that the difference in context between acquisition and extinction results in the extinction context's failing to retrieve the acquisition memory. Similarly, generalization decrement theories propose that extinction occurs because there is a progressive dissimilarity between the context of acquisition and extinction that prevents the CS from retrieving its excitatory association (Capaldi, 1967, 1994). Consequently, both theories predict that the restoration of the acquisition context and/or 
the elimination of the context of extinction will result in the recovery of responding after extinction. In the case of concurrent recovery, the presentation of a new discrete CS paired with the US may constitute a partial return to the circumstances under which the original CS-US memory was formed, and hence allows for the retrieval of the original excitatory association.

Although contextual control theories have been used to explain a wide variety of phenomena in extinction and recovery, there are three problems with contextual control theories posed by the present results. First, it is not apparent why presentations of the US alone were insufficient to restore the acquisition context whereas presentations of a novel CSB paired with the same US were sufficient. Bouton's (1994) theory and, even more so, Capaldi's $(1967,1994)$ generalization decrement theory contend that the US is the main source of internal contextual cues during CS-US pairings. Even if the presence of CSB and the acquisition of CRs did help restore the context of acquisition, it is difficult to square the substantial recovery of CRs to CSA during CSB-US pairings with the absence of discernible reinstatement of CRs when the US alone was presented.

Second, contextual control theories of recovery are readily applicable when there is a pronounced change between the context of extinction and the context in which recovery occurs. However, this explanation becomes tenuous when the global and local contexts for acquisition, extinction, and recovery of responding are very similar. For example, in Experiment 1 extinction in the unpaired condition was obtained by increasing the CSA-US interval from $200 \mathrm{msec}$ to $30 \mathrm{sec}$. The sequence of events and overall CS-US contingency remained constant. Subsequently, when CSB was paired with the US during Stage 3 in Group U-CMA, the temporal relationship between the CS and the US was restored, albeit with a completely different CS. Hence, the change in context from each stage to the next could be construed as relatively small. Nevertheless, during CSB-US pairings, there was recovery of responding to the extinguished CSA after unpairings, and this recovery was just as great as recovery after CSA-alone extinction in Group E-CMA.

Third, contextual control theories cannot explain why concurrent recovery was reduced when CSB had been previously paired with the US during initial acquisition training in Group 240B + in Experiment 3. According to the contextual control theories, the reintroduction of the CSB-US pairings should have been more similar to the context of acquisition than to the conditions in which CSB itself and CSB-US pairings were novel occurrences. If anything, recovery of CRs to CSA should have been enhanced by prior CBS-US pairings.

The difficulties faced by contextual control theories in explaining the present results may be related to the ineffectiveness of the brief electrodermal US to act as a contextual cue for the rabbit NM response, or its absence. According to generalization decrement theories, the effectiveness of a reinforcer to act as a contextual cue can be ascertained by demonstrating single-alternation learning. In a single-alternation schedule, reinforced CS-US trials (Rs) are strictly alternated with nonreinforced CS-alone trials (Ns). Hence, in an $\mathrm{R} \rightarrow \mathrm{N}$ sequence the US in the R trial is a local contextual cue that the CS in the $\mathrm{N}$ trial will not be reinforced. Conversely, in an $\mathrm{N} \rightarrow \mathrm{R}$ sequence the absence of the US in the $\mathrm{N}$ trial is a cue that the CS in the R trial will be reinforced. The rabbit NM preparation has shown single alternation learning, but only under highly restricted conditions - namely, when the interval in the $\mathrm{R} \rightarrow \mathrm{N}$ sequence was $10 \mathrm{sec}$ and the interval in the $\mathrm{N} \rightarrow \mathrm{R}$ sequence was $60 \mathrm{sec}$ (Hoehler \& Leonard, 1973).

\section{Changes in the Relative Associative Strengths of the CS and Its Context}

Another class of theories has also described context as playing an important role in acquisition and extinction, but without relying on the US as a source of cues (Miller \& Matzel, 1988; Wagner \& Brandon, 1989). These theories assume that the context provided by the experimental apparatus independently acquires and loses excitatory strength that in turn modulates responding to a CS. Among them, the comparator theory (Denniston, Savastano, \& Miller, 2001; Gibbon \& Balsam, 1981; Miller \& Matzel, 1988) makes the additional assumption that the CS and its context form a bidirectional excitatory association during their pairings with the US. Comparator theory further assumes that, through this association, the context modulates responding to the CS in a negative fashion. That is, the CS is thought to activate both its associative strength and the associative strength of the context. Consequently, overt responding would reflect the difference between the excitatory strength of the CS versus that of its training context, even when the CS was tested elsewhere. Hence, any increase in the excitatory strength of the training context would diminish responding to the CS, and any decrease in the excitatory strength of the training context would increase responding to the CS.

Comparator theory has considerable difficulty in explaining concurrent recovery. Comparator theory explicitly excludes the formation of inhibitory associations. Thus, to explain extinction of the CR, the theory would have to assume that the excitatory associative strength of CSA declines during extinction training. Hence, after thorough extinction there should be little or no excitatory associative strength to be retrieved by CSA during subsequent CSB-US pairings. If, for some reason, the context-US association did not decline or declined more slowly during extinction, overt responding to CSA might disappear before its excitatory strength had entirely been lost. Nevertheless, comparator theory does not provide any mechanism by which the context-US association could protect the CSA-US association from ultimately diminishing to zero. In the present experiments, extinction of CSA was always carried beyond the point at which all responding to CSA had ceased, and concurrent recovery 
still appeared. Recently, Weidemann and Kehoe (2003) observed robust concurrent recovery after massive extinction, in which there were $27 \mathrm{CSA}$-alone trials for every initial CSA-US training trial.

\section{Changes in Expression of Excitatory Associations}

One of the oldest types of mechanisms used to explain phenomena such as spontaneous recovery, renewal, and reinstatement is the hypothesis that the expression of the excitatory association established during acquisition training is masked during extinction. This masking of expression can take many forms, including the establishment of an inhibitory CS-US association, a loss of attention to the CS, a loss in the effective value of the US, or an increase in the threshold for expression of the CR. Accordingly, recovery of responding after extinction occurs when the mask is removed.

Inhibitory associations. Pavlov (1927) postulated that the disappearance of responding during extinction is the result of inhibition localized in the cortical encoding of the CS. Konorski (1948) subsequently provided a more detailed explanation of the mechanism of extinction. According to Konorski, the establishment of an inhibitory connection results from the CS's being present when the US cortical center undergoes a fall in activation. In extinction, the inhibitory connection is formed side by side with the totally preserved excitatory connection. The process of extinction stops when all the excitatory activation is counterbalanced by the inhibitory process, so that no activation of the US center occurs when the CS center is excited. Following extinction, the removal of the inhibitory association would result in a complete restoration of responding to the extinguished CS.

Although the acquisition and removal of inhibition can in principle explain the loss and recovery of responding to a CS, this theoretical approach has always been unclear as to how inhibition is removed. Pavlov (1927) supposed that inhibition was more labile and easily disrupted than excitation. However, Konorski (1948) and later theorists have assumed that the formation of inhibitory associations follows the same rules as the formation of excitatory associations (Klopf, 1988; Macrae \& Kehoe, 1999). According to this approach, the extinction of the inhibitory association would be contingent on the CS's presence during the activation of the US center. Alternatively, inhibition could be overcome by the acquisition of additional CS-US excitatory strength (Rescorla, 2001). Regardless of how inhibition might be removed or overcome when retraining is conducted with the original CS, this theoretical approach cannot readily explain either facilitated cross-modal acquisition or concurrent recovery. When training with the new CSB is started, it is difficult to see how an inhibitory association established during extinction with CSA could have a positive effect on acquisition to CSB. Conversely, there is no reason why training with CSB would cause the inhibitory association formed during CSA extinction to be weak- ened or overcome and hence allow for the expression of CSA's original excitatory association.

Changes in CS processing. Theories of selective attention contend that there must be a minimal level of CS processing for both learning (Mackintosh, 1975; Pearce \& Hall, 1980) and its expression (Lubow, 1989; Lubow, Weiner, \& Schnur, 1981; Mackintosh, 1975). These theories further assume that attention to a CS is not fixed but can change from one trial to the next depending on both prior exposure to the CS and the magnitude of associative change in either direction. These theories uniformly suppose that CS-alone exposures will ultimately drive down attention, making it difficult for the CS to undergo further associative change and to activate any existing associative strength. In the case of extinction, these two consequences of the reduction in CS processing should have a paradoxical effect. On the one hand, the reduction in associative change should tend to preserve the excitatory strength of the CS and/or prevent the acquisition of inhibitory strength. On the other hand, the reduction in response expression should prevent the remaining net excitatory strength from being expressed.

This paradoxical effect allows selective attention theory to explain rapid reacquisition. As the reintroduction of CS-US pairings raises attention to the CS, the underlying associative strength could then be expressed. However, it is unclear how selective attention theory would explain either facilitated cross-modal acquisition to CSB or concurrent recovery of responding to test presentations of the original, but now extinguished, CSA. The problem lies in the central assumption that changes in attention are specific to each CS. Changes in attention to one CS would not be expected to transfer to other CSs, particularly CSs in other modalities. Hence, there is no way for the reduced attention to the extinguished CS to rise and expose its residual excitatory strength. As one potential solution to CS specificity, older attentional theories (Sutherland \& Mackintosh, 1971) presume that "attention" is acquired to "analyzers" rather than to specific CSs. These analyzers, however, are usually operationalized in terms of physical stimulus dimensions, such as tone frequency, for example (Sutherland \& Mackintosh, 1971, p. 33). Although multidimensional analyzers are conceivable, postulation of a superordinate analyzer that would transfer among all the distinct dimensions of auditory, visual, and tactile stimuli would vacate the concept of "analyzer" of all meaning and convert attentional theory into a redescription of the data.

Lubow's (1989) conditioned attention theory does offer some scope for explaining cross-modal effects. His theory includes a mechanism based on external inhibition. Specifically, presentation of an extraneous stimulus can temporarily elevate attention during any subsequent stimulus presentations. Hence, the introduction of a novel CSB could raise attention to CSA, thus producing concurrent recovery for responding to CSA during CSB-US pairings. Moreover, Lubow's theory also explains why the amount of recovery to CSA was reduced 
by earlier CSB-US pairings in Stage 1. When CSB is initially paired with the US, there would be an increase in the attention to CSB, but over repeated CSB-US pairings attention to CSB would inevitably decline. Thus, when CSB-US pairings are recommenced in Stage 3, CSB would no longer be novel and would have a weaker disinhibiting effect. However, the external disinhibition mechanism cannot explain how acquisition to CSB itself is facilitated by prior CSA-US pairings. There is nothing in Lubow's theory in particular or selective attention theories in general to suggest that CSB would ever start training in Stage 3 with an elevated level of attention.

Changes in US processing. Rescorla and Heth (1975) proposed that the magnitude and quality of the US representation affect the expression of a CS-US association. That is, overt responding is a product of the strength of the CS-US association and the integrity of the US representation activated through the associative linkage. During extinction, the US representation is postulated to deteriorate as a result of its being activated by the CS in the absence of the actual US. Hence, responding could decline without there being either a reduction in the excitatory associative strength or the acquisition of an inhibitory association. However, Rescorla and Heth postulated that the US representation can be quickly reestablished by presentation of the US, either alone or in CS-US pairings. The complete absence of reinstatement following US presentations in the present set of experiments is not conducive to an explanation of extinction based on changes in US representations, at least as conceived by Rescorla and Heth.

With considerable modification and elaboration, however, a model of extinction based on changes in US representation comes closer to explaining the present results. Specifically, Weidemann and Kehoe (2003) presented a model in which the US representation is subject to conditioning-specific modification. Evidence of such modifications is that Schreurs, Oh, Hirashima, and Alkon (1995) have found that, following asymptotic classical conditioning of the rabbit NM response, the peak latency and the amplitude of URs increased when the US was tested alone in the absence of the CS. These changes in the US-UR reflex were a result of prior CS-US pairings and did not appear following either explicit unpairings of the CS and US or exposure to the experimental apparatus (cf. Buck, Seager, \& Schreurs, 2001; Gruart \& Yeo, 1995; Schreurs et al., 2000).

Weidemann and Kehoe (2003) proposed that the US representation increases when there is a positive change in associative strength and diminishes when there is a negative change in associative strength. Whereas Rescorla and Heth (1975) assumed that the US representation affects only the expression of associative strength, Weidemann and Kehoe (2003) assume that the US representation affects both the rate of learning and its expression. Simulations revealed that this model could readily explain rapid reacquisition and facilitated cross-modal acquisition. To a lesser extent, the model could also generate concurrent recovery in the absence of US reinstatement. However, the level of concurrent recovery, even with considerable tweaking of the parameters, was never as great as that seen in the present or previous studies (Macrae \& Kehoe, 1999; Weidemann \& Kehoe, 2003).

Changes in CR expression. During CS-US training, the acquisition of an excitatory association may be accompanied by a reduction in a threshold for activating the CR. Conversely, during extinction the activation of the $\mathrm{CR}$ in the absence of a reinforcer would tend to increase the threshold for CR activation and make it increasingly difficult to elicit a CR, even if the excitatory association was still intact (Rescorla, 1997). This change in the CR threshold would be independent of the eliciting stimulus. Thus, extinction would produce a general loss of responding in all CSs that elicit a particular CR. The loss of responding to CSB during extinction of responding to CSA in Experiment 3 was consistent with this hypothesis. After extinction, subsequent CS-US pairings would once again lower the CR threshold. Therefore, pairing any CS with the US would restore responding to all extinguished CSs, which would explain the recovery of responding to CSA during CSB-US training in Stage 3 of the present experiments.

Changes in CR expression may be a major contributor to extinction and recovery, but a purely CR-based model cannot explain all of the present results, particularly those of Experiment 3. In particular, at the end of Stage 2, responding to CSA was entirely extinguished in both Groups 240B+ and 0B+, and, at the start of Stage 3 responding to CSB in both groups was negligible. On the face of it, the two groups would appear to have had their thresholds for expressing the CR raised to at least an equally high level. Conceivably, the threshold of Group $240 \mathrm{~B}+$ might be lower than that of Group $0 \mathrm{~B}+$ as a consequence of Group 240B +'s greater overall history of CS-US pairings. Accordingly, Group 240B + should have shown the same or a greater amount of recovery of responding to CSA during CSB-US pairings in Stage 3. In fact, contrary to this prediction, the recovery of responding to CSA in Group 240B + was less than that in Group 0B+.

\section{Changes in the Excitatory Associations}

As has been seen in Experiment 2 as well as in previous studies described in the introduction (Kehoe, 1992; Macrae \& Kehoe, 1999), concurrent recovery does not arise from unlearned generalization across modalities. Nevertheless, it is hard to avoid the impression that there is some form of generalization. Because concurrent recovery appears only to a CS that has itself been previously paired with the US, concurrent recovery may reflect some form of generalization acquired through the pairing of both the target stimulus (CSA) and the final training stimulus (CSB) with the US. 
Layered neural networks offer a promising means for explaining changes in generalization as a result of learning history. An example of such a layered network is shown in Figure 7. This network is an extension of Kehoe's (1988) model of conditioning (see also Kehoe, 1986; Schreurs \& Kehoe, 1987). This network contains two sensory receptors, one for a tone CS and one for a light CS. Each of these inputs has a fixed input (solid line with arrow) to its own neuron-like unit, labeled "T" (tone) and "L" (light), respectively. ${ }^{1}$

As is common in layered networks, the $\mathrm{T}$ and $\mathrm{L}$ units each send projections to two intermediate, "hidden" units $(\mathrm{X}, \mathrm{Y})$. These connections with the hidden units are subject to associative changes depending on inputs from the US to the $\mathrm{X}$ and $\mathrm{Y}$ units. In turn, the $\mathrm{X}$ and $\mathrm{Y}$ units send projections to an output unit (R), from which the $\mathrm{CR}$ is generated. These connections are also subject to associative change. The US provides a "teacher" input that triggers the $\mathrm{X}, \mathrm{Y}$, and $\mathrm{R}$ units on reinforced trials. In this network, training with even a single CS (e.g., tone) could produce the acquisition of multiple, parallel linkages in the exterior layer (e.g., T-X, T-Y) and interior layer $(\mathrm{X}-\mathrm{R}, \mathrm{Y}-\mathrm{R})$.

According to this model, the acquisition of a CR to a single CS depends on strengthening of the connections in series. For example, strengthening of the $\mathrm{T}-\mathrm{X}$ and $\mathrm{X}-\mathrm{R}$ connections would produce $\mathrm{CR}$ acquisition to a tone CS. Strengthening of the $\mathrm{T}-\mathrm{Y}$ and $\mathrm{Y}-\mathrm{R}$ connections would also produce $\mathrm{CR}$ acquisition. Subsequent to the formation of these connections, introduction of a new CS-namely, light - would be subject to more rapid acquisition, because as the $\mathrm{L}-\mathrm{X}$ and $\mathrm{L}-\mathrm{Y}$ connections are established, they can capitalize on the existing $\mathrm{X}-\mathrm{R}$ and $\mathrm{Y}-\mathrm{R}$ connections.

The same structures allow for the preservation of considerable associative strength during extinction and hence for rapid reacquisition and the facilitation of cross-modal acquisition even after extinction. Such preservation can occur because Kehoe's (1988) learning mechanism assumes that a change in the connection weight between any pair of units is determined by the discrepancy be- tween (1) associative input, which is a product of the level of activation from the upstream unit and its connection weight to the downstream unit, and (2) the level of activation from the US input to the downstream unit (cf. Rescorla \& Wagner, 1972; Sutton \& Barto, 1981). Hence, an upstream unit must be active for any of its downstream connections to be affected by the presence or absence of the US. (As may be apparent, this algorithm differs dramatically from the back-propagation algorithm, in which changes in connection weights throughout the network depend on the discrepancy between the final output from the network and the desired output specified by a teacher input [Rumelhart, Hinton, \& Williams, 1986].)

At the beginning of extinction with an established tone $\mathrm{CS}$, both the exterior $(\mathrm{T}-\mathrm{X}, \mathrm{T}-\mathrm{Y})$ and interior $(\mathrm{X}-\mathrm{R}$, $\mathrm{Y}-\mathrm{R}$ ) connections would start to diminish at about the same rate. As the $\mathrm{T}-\mathrm{X}$ and $\mathrm{T}-\mathrm{Y}$ connections become too weak to activate the $\mathrm{X}$ and $\mathrm{Y}$ units, respectively, the interior connections $(\mathrm{X}-\mathrm{R}, \mathrm{Y}-\mathrm{R})$ would be protected from further extinction. Consequently, a large portion of the interior connections would be preserved. Subsequent training with either the tone or the light would capitalize on these preserved connections to produce both rapid reacquisition to the original, tone $\mathrm{CS}$ and facilitated cross-modal acquisition to a new, light CS. However, the preservation of the interior connections does not explain how training with a cross-stimulus such as the new, light CS would result in recovery of responding to the original, tone CS.

Potential solutions to this conundrum revolve around two key aspects of the model: the degree to which each sensory unit is able to activate each hidden unit and the nature of the learning rule. First, each sensory unit may be assumed to favor one particular hidden unit. In terms of the model's parameters, the rate of associative change between the $\mathrm{T}$ unit and the $\mathrm{X}$ hidden unit would be greater than that between the $\mathrm{T}$ unit and the $\mathrm{Y}$ hidden unit. Thus, during initial acquisition with the tone stimulus, the $\mathrm{T}-\mathrm{X}$ and $\mathrm{T}-\mathrm{Y}$ connections would both develop excitatory strength, but the $\mathrm{T}-\mathrm{X}$ connection would acquire associa-

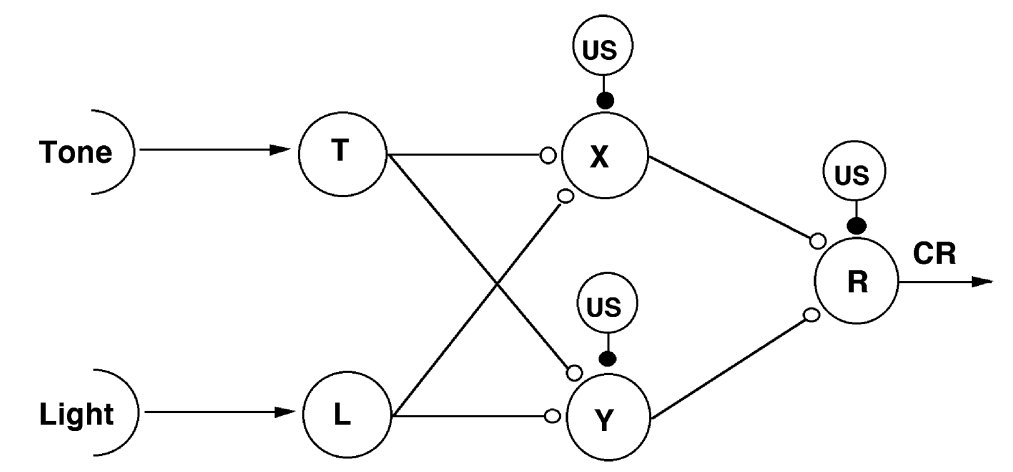

Figure 7. A connectionist model for acquisition, extinction, cross-modal acquisition, and recovery in classical conditioning. It contains the three sensory inputs of tone (T), light (L), and unconditioned stimulus (US), and three adaptive units $(X, Y$, and $R)$. 
tive strength faster than the $\mathrm{T}-\mathrm{Y}$ connection would. Conversely, the L input would favor the L-Y connection relative to the $\mathrm{L}-\mathrm{X}$ connection. Second, with respect to the learning rule for each unit, competition among simultaneous inputs would allow more strongly activated connections to capture greater associative strength to the detriment of less strongly activated connections (Kehoe, 1988; Rescorla \& Wagner, 1972; Sutton \& Barto, 1981). Consequently, if training were conducted using the $\mathrm{T}$ input, the interior $\mathrm{X}-\mathrm{R}$ connection would reach a higher terminal strength than the $\mathrm{Y}-\mathrm{R}$ connection, because the rapid acquisition of the $\mathrm{T}-\mathrm{X}$ connection would initially produce a strong input to the $\mathrm{R}$ unit via the $\mathrm{X}-\mathrm{R}$ connection. At the same time, the low rate of acquisition for the $\mathrm{T}-\mathrm{Y}$ connection would disadvantage the $\mathrm{Y}-\mathrm{R}$ connection.

Subsequent extinction training using the T input would result in a decrease in the associative strength of all the connections. However, the larger rate of change in the $\mathrm{T}-\mathrm{X}$ connection would produce a larger loss of associative strength in the $\mathrm{T}-\mathrm{X}$ connection than in the $\mathrm{T}-\mathrm{Y}$ connection, with its smaller rate of change. Once the $\mathrm{T}-\mathrm{X}$ connection was significantly reduced, the $\mathrm{X}-\mathrm{R}$ connection would be largely protected from further decreases. Meanwhile, the Y-R connection would decrease toward zero but only slowly. At the end of extinction, the T-X connection would be largely eliminated, but the $\mathrm{X}-\mathrm{R}$ connection would still possess associative strength. Paradoxically, the $\mathrm{T}-\mathrm{Y}$ connection would have retained its strength, but, as a consequence, the $\mathrm{Y}-\mathrm{R}$ connection strength would have been eliminated. Hence, neither the $\mathrm{T}-\mathrm{X}-\mathrm{R}$ nor the $\mathrm{T}-\mathrm{Y}-\mathrm{R}$ pathway would be able to generate an output from the $\mathrm{R}$ unit.

Cross-modal training with the $\mathrm{L}$ input would result in the establishment of $\mathrm{L}-\mathrm{X}$ and $\mathrm{L}-\mathrm{Y}$ connections as well as reestablishment of the $\mathrm{Y}-\mathrm{R}$ connection. Reestablishment of the $\mathrm{Y}-\mathrm{R}$ connection in conjunction with the positive $\mathrm{T}-\mathrm{Y}$ connection would result in the ability of the tone stimulus to activate the $\mathrm{R}$ unit and thus recover at least some responding to the extinguished $\mathrm{T}$ input. Initial simulations, available from the authors, with hand-crafted learning rates have demonstrated that the apparent changes in cross-modal generalization indicated by concurrent recovery can be implemented in a layered neural network. Furthermore, the initial simulations revealed that the network can also explain the diminution of concurrent recovery seen when CSB-US training was inserted between CSA-US training and CSA- extinction training. This outcome was a result of complicated interactions among the competing connections in both layers across stages of training. At this point, the simulations are highly parameter dependent, but they were sufficiently successful to provide a proof of concept - namely, that the apparent changes in cross-modal generalization can be implemented in a conventional layered network.

\section{Conclusions}

Extinction and recovery from extinction may be mediated by several mechanisms. Robbins (1990) suggested that a fruitful strategy is to estimate the contribution of each mechanism in each response system under different conditions (Kehoe \& White, 2002). To explain the full pattern of the present results, some mechanisms can be discounted as major contributors, some are questionable, and some seem plausible.

In particular, contextual control mechanisms can largely be discounted as contributors to cross-modal transfer between CSs, including facilitated cross-modal acquisition, concurrent recovery, and secondary extinction, especially in the absence of reinstatement of CRs by US-alone presentations. The brief electrodermal US itself does not appear to produce sufficiently long-lasting changes in the context. One could argue that CS-US pairings and consequent CR acquisition produce a "context of acquisition," but such an attempt to defend contextual control mechanisms risks converting them to nothing more than redescriptions of the known findings. In contrast to USdependent theories of contextual control, comparator theory does not require that the US contribute to the context. Nevertheless, comparator theory faces fundamental difficulties in explaining how context-US associations would preserve CS-US associative strength during extinction.

Mechanisms related to CR expression vary in their plausibility. Mechanisms of inhibitory learning appear to play little role in cross-modal transfer between CSs. CS processing theories face the same difficulties to the extent that they assume that attentional/associability mechanisms are stimulus specific. Lubow's (1989; Lubow et al., 1981) conditioned attention mechanism, which allows for widespread elevation of attention, may contribute to concurrent recovery and secondary extinction. Changes in US processing, provided they depend on CS-US pairings, may make major contributions to crossmodal effects (Weidemann \& Kehoe, 2003). Furthermore, changes in CR threshold may also contribute to extinction and recovery from extinction.

Models that presume that unlearning underpins extinction have traditionally been thought to be unable to account for any recovery after extinction. However, layered networks allow for the protection of associative strength and can explain rapid reacquisition and facilitated cross-modal acquisition after extinction (Kehoe, 1988). As has been shown above, an extension of a previous layered network model can produce some degree of concurrent recovery. Furthermore, there is no obstacle to incorporating mechanisms related to CS processing, US representation, and CR threshold into a layered network model (Kehoe \& White, 2002). Although at risk of overdetermination, these mechanisms may amplify each other to produce the substantial concurrent recovery seen in the present experiments.

\section{REFERENCES}

Bouton, M. E. (1988). Context and ambiguity in the extinction of emotional learning: Implications for exposure therapy. Behaviour Research \& Therapy, 26, 137-149.

Bouton, M. E. (1994). Conditioning, remembering and forgetting. Journal of Experimental Psychology: Animal Behavior Processes, 20,219-231. 
Bouton, M. E., \& Bolles, R. C. (1979). Contextual control of the extinction of conditioned fear. Learning \& Motivation, 10, 445-466.

Buck, D. L., Seager, M. A., \& Schreurs, B. G. (2001). Conditioningspecific reflex modification of the rabbit (Oryctolagus cuniculus) nictitating membrane response: Generality and nature of the phenomenon. Behavioral Neuroscience, 115, 1039-1047.

CAPALDI, E. J. (1967). A sequential hypothesis of instrumental learning. In K. W. Spence \& J. T. Spence (Eds.), The psychology of learning and motivation (Vol. 1, pp. 67-91). New York: Academic Press.

CAPALDI, E. J. (1994). The sequential view: From rapidly fading stimulus traces to the organization of memory and the abstract concept of number. Psychonomic Bulletin \& Review, 1, 156-181.

Denniston, J. C., Savastano, H. I., \& Miller, R. R. (2001). The extended comparator hypothesis: Learning by contiguity, responding by relative strength. In R. R. Mowrer \& S. B. Klein (Eds.), Handbook of contemporary learning theories (pp. 65-117). Mahwah, NJ: Erlbaum.

Frey, P. W., \& Butler, C. S. (1977). Extinction after aversive conditioning: An associative or nonassociative process? Learning \& $\mathrm{Mo}$ tivation, 8, 1-17.

GiBBON, J., \& BALSAM, P. (1981). Spreading association in time. In C. M. Locurto, H. S. Terrace, \& J. Gibbon (Eds.), Autoshaping and conditioning theory (pp. 219-253). New York: Academic Press.

GifTAKIS, J. E., \& TAIT, R. W. (1998). Blocking of the rabbit's classically conditioned nictitating membrane response: Effects of modification of contextual assocative strength. Learning \& Motivation, 29, 23-48.

Gormezano, I. (1966). Classical conditioning. In J. B. Sidowski (Ed.), Experimental methods and instrumentation in psychology (pp. 385420). New York: McGraw-Hill.

Gormezano, I., \& GibBs, C. M. (1988). Transduction of the rabbit's nictitating membrane response. Behavior Research Methods, Instrumentation, \& Computers, 20, 18-21.

Gormezano, I., Kehoe, E. J., \& Marshall, B. S. (1983). Twenty years of classical conditioning research with the rabbit. In J. M. Sprague \& A. N. Epstein (Eds.), Progress in psychobiology and physiological psychology (Vol. 10, pp. 197-275). New York: Academic Press.

Gruart, A., \& Yeo, C. H. (1995). Cerebellar cortex and eyeblink conditioning: Bilateral regulation of conditioned responses. Experimental Brain Research, 104, 431-448.

HARRIS, R. J. (1994). ANOVA: An analysis of variance primer. Itasca, IL: Peacock.

Hinson, R. E. (1982). Effects of UCS preexposure on excitatory and inhibitory rabbit eyelid conditioning: An associative effect of conditioned contextual stimuli. Journal of Experimental Psychology: Animal Behavior Processes, 8, 49-61.

HoEHLER, F. K., \& LEONARD, D. W. (1973). Classical nictitating membrane conditioning in the rabbit (Oryctolagus cuniculus): Single alternation with differential intertrial intervals. Journal of Comparative \& Physiological Psychology, 85, 277-288.

KEHOE, E. J. (1986). A layered network model for learning-to-learn and configuration in classical conditioning. In C. Clifton (Ed.), Proceedings of the eighth annual conference of the Cognitive Science Society (pp. 154-175). Hillsdale, NJ: Erlbaum.

KEHOE, E. J. (1988). A layered network model of associative learning: Learning to learn and configuration. Psychological Review, 95, 411 433.

KeHOE, E. J. (1992). Versatility in conditioning: A layered network model. In D. S. Levine \& S. J. Levin (Eds.), Motivation, emotion and goal direction in neural networks (pp. 63-90). Hillsdale, NJ: Erlbaum.

Kehoe, E. J., Horne, A. J., \& Macrae, M. (1995). Learning to learn: Real-time features and a connectionist model. Adaptive Behavior, 3, 235-271.

Kehoe, E. J., \& Macrae, M. (2002). Fundamental behavioral methods and findings in classical conditioning. In J. W. Moore (Ed.), A neuroscientist's guide to classical conditioning. New York: Springer-Verlag.

KeHoe, E. J., \& White, N. E. (2002). Extinction revisited: Similarities between extinction and reductions in US intensity in classical conditioning of the rabbit's nictitating membrane response. Animal Learning \& Behavior, 30, 96-111.

KLOPF, A. H. (1988). A neuronal model of classical conditioning. Psychobiology, 16, 85-125.
KonORSKI, J. (1948). Conditioned reflexes and neuronal organization. Cambridge: Cambridge University Press.

Lashley, R. L., Richardson, R., \& Riccio, D. C. (1987). ACTH- and noncontingent footshock-induced recovery of an extinguished passive avoidance response. Physiology \& Behavior, 40, 677-680.

Lubow, R. E. (1989). Latent inhibition and conditioned attention theory. Cambridge: Cambridge University Press.

Lubow, R. E., Weiner, I., \& SCHNur, P. (1981). Conditioned attention theory. In G. H. Bower (Ed.), The psychology of learning and motivation (Vol. 15, pp. 1-49). San Diego: Academic Press.

Mackintosh, N. J. (1975). A theory of attention: Variation in the associability of stimuli with reinforcement. Psychological Review, $\underline{\mathbf{8 2}}_{2}$ 276-298.

MACRAE, M., \& Kehoe, E. J. (1995). Transfer between conditional and discrete discriminations in conditioning of the rabbit nictitating membrane response. Learning \& Motivation, 26, 380-402.

Macrae, M., \& KeHOE, E. J. (1999). Savings after extinction in conditioning of the rabbit's nictitating membrane response. Psychobiology, 27, 85-94.

MARShall-Goodell, B., Schreurs, B. G., \& Gormezano, I. (1982). Ruler vs. the Apple II/FIRST system analysis of analog signals in classical conditioning. Behavior Research Methods \& Instrumentation, 14, 519-525.

Miller, R. R., \& Matzel, L. D. (1988). The comparator hypothesis: A response rule for the expression of associations (Vol. 22). San Diego: Academic Press.

Napier, R. M., Macrae, M., \& Kehoe, E. J. (1992). Rapid reacquisition in conditioning of the rabbit's nictitating membrane response. Journal of Experimental Psychology: Animal Behavior Processes, 18, 182-192.

O'BRIEN, R. G., \& KAISER, M. K. (1985). MANOVA method for analyzing repeated measures designs: An extensive primer. Psychological Bulletin, 97, 316-333.

Pavlov, I. P. (1927). Conditioned reflexes (G. V. Anrep, Trans.). London: Oxford University Press.

Pearce, J. M., \& Hall, G. (1980). A model for Pavlovian learning: Variations in the effectiveness of conditioned but not of unconditioned stimuli. Psychological Review, 87, 532-552.

ResCorla, R. A. (1967). Pavlovian conditioning and its proper control procedures. Psychological Review, 74, 71-80.

RESCORLA, R. A. (1997). Response-inhibition in extinction. Quarterly Journal of Experimental Psychology, 50B, 238-252.

RESCORLA, R. A. (2001). Retraining of extinguished Pavlovian stimuli. Journal of Experimental Psychology: Animal Behavior Processes, 27, 115-124.

RESCORLA, R. A., \& HeTH, C. D. (1975). Reinstatement of fear to an extinguished conditioned stimulus. Journal of Experimental Psychology: Animal Behavior Processes, 1, 88-96.

Rescorla, R. A., \& Wagner, A. R. (1972). A theory of Pavlovian conditioning: Variations in the effectiveness of reinforcement and nonreinforcement. In A. H. Black \& W. F. Prokasy (Eds.), Classical conditioning II (pp. 64-99). New York: Appleton-Century-Crofts.

Richardson, R., Duffield, T. Q., Bailey, G. K., \& Westbrook, R. F. (1999). Reinstatement of fear to an extinguished conditioned context. Animal Learning \& Behavior, 27, 399-415.

RobBINS, S. J. (1990). Mechanisms underlying spontaneous recovery in autoshaping. Journal of Experimental Psychology: Animal Behavior Processes, 16, 235-249.

Rumelhart, D. E., Hinton, G. E., \& Williams, R. J. (1986). Learning internal representations by error propagation. In D. E. Rumelhart, J. L. McClelland, and the PDP Research group (Eds.), Parallel distributed processing: Explorations in the microstructures of cognition (Vol. 1, pp. 318-362). Cambridge, MA: MIT Press.

Saladin, M. E., \& TAIT, R. W. (1986). US preexposures retard excitatory and facilitate inhibitory conditioning of the rabbit's nictitating membrane response. Animal Learning \& Behavior, 14, 121-132.

ScAndrett, J., \& Gormezano, I. (1980). Microprocessor control and A/D data acquisition in classical conditioning. Behavior Research Methods \& Instrumentation, 12, 120-125.

Schreurs, B. G. (1993). Long-term memory and extinction of the clas- 
sically conditioned rabbit nictitating membrane response. Learning \& Motivation, 24, 293-302.

SchreURS, B. G. (1998). Long-term memory and extinction of rabbit nictitating membrane trace conditioning. Learning \& Motivation, 29, 68-82.

SchreURs, B. G., \& Kehoe, E. J. (1987). Cross-modal transfer as a function of initial training level in classical conditioning with the rabbit. Animal Learning \& Behavior, 15, 47-54.

Schreurs, B. G., Oh, M. M., Hirashima, C., \& Alkon, D. L. (1995). Conditioning-specific modification of the rabbit's unconditioned nictitating membrane response. Behavioral Neuroscience, 109, 24-33.

Schreurs, B. G., Shi, T., Pineda III, S., \& BuCK, D. L. (2000). Conditioning the unconditioned response: Modification of the rabbit's (Oryctolagus cuniculus) unconditioned nictitating membrane response. Journal of Experimental Psychology: Animal Behavior Processes, 26, 144-156.

SUTHERLAND, N. S., \& MACKINTOSH, N. J. (1971). Mechanisms of animal discrimination learning. New York: Academic Press.

Sutton, R. S., \& BARTO, A. G. (1981). Toward a modern theory of adaptive networks: Expectation and prediction. Psychological Review, 88, 135-170.

WAGNER, A. R., \& BRANDON, S. E. (1989). Evolution of a structured connectionist model of Pavlovian conditioning (AESOP). In S. B. Klein \& R. R. Mowrer (Eds.), Contemporary learning theories: Pavlovian conditioning and the status of traditional learning theory. Hillsdale, NJ: Erlbaum.
Weidemann, G., \& Kehoe, E. J. (1997). Transfer and counterconditioning of conditional control in the rabbit nictitating membrane response. Quarterly Journal of Experimental Psychology, 50B, 295-316.

WeidemanN, G., \& Kehoe, E. J. (2003). Savings in classical conditioning in the rabbit as a function of extended extinction. Learning \& Behavior, 31, 49-68.

\section{NOTE}

1. Given the role that contextual processes may play in conditioning, the inclusion of inputs for only the discrete CSs (tone and light) is deliberately a simplifying assumption. At present, the exact role of context in rabbit NM conditioning is unclear. Among the present results, the complete absence of US-induced reinstatement (Experiment 1) suggests no role for contextual processes in recovery of responding. Likewise, the absence of cross-modal generalization between tone and light (Experiment 2) suggests that the context does not contribute a common element to the tone and light inputs. However, the possible extinctive effect of apparatus exposure (Experiment 3) indicates that ultimately a complete model of rabbit NM conditioning will require inputs for contextual cues.

(Manuscript received October 31, 2003; revision accepted for publication April 19, 2004.) 